NASA Technical Memorandum 100245

\title{
Creep Life Prediction Based on Stochastic Model of Microstructurally Short Crack Growth
}

Takayuki Kitamura

Lewis Research Center

Cleveland, Ohio

and

Ryuichi Ohtani

Kyoto University

Kyoto, Japan

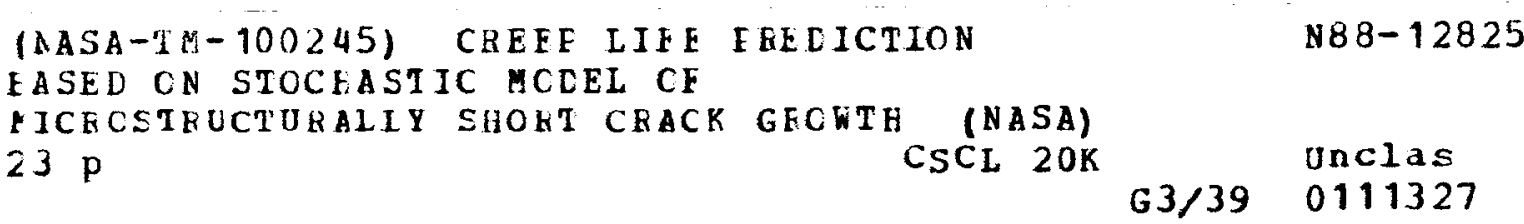

Prepared for the

Summer Annual Meeting of the American Society of Mechanical Engineers

Berkeley, California, June 20-22, 1988 


\title{
CREEP LIFE PREDICTION BASED ON STOCHASTIC MODEL OF MICROSTRUCTURALLY
}

\author{
SHORT CRACK GROWTH \\ Takayuki Kitamura* \\ National Aeronautics and Space Administration \\ Lewis Research Center \\ Cleveland, Ohio 44135 \\ and \\ Ryuichi Ohtani \\ Kyoto University \\ Department of Engineering Science \\ Kyoto, Japan
}

\section{SUMMARY}

A nondimensional model of microstructurally short crack growth in creep is developed based on a detailed observation of the creep fracture process of 304 stainless steel. In order to deal with the scatter of small crack growth rate data caused by microstructural inhomogeneity, a random variable technique is used in the model. A cumulative probability of the crack length at an arbitary time, $G(\bar{a}, \bar{t})$, and that of the time when a crack reaches an arbitary length, $F(\bar{t}, \bar{a})$, are obtained numerically by means of a Monte Carlo method. $G(\bar{a}, \bar{t})$ and $F(\bar{t}, \bar{a})$ are the probabilities for a single crack. However, multiple cracks generally initiate on the surface of a smooth specimen from the early stage of creep life to the final stage. Taking into account the multiple crack initiations, the actual crack length distribution observed on the surface of a specimen is predicted by the combination of probabilities for a single crack. The prediction shows a fairly good agreement with the experimental result for creep of 304 stainless steel at $923 \mathrm{~K}$. The probability of creep life is obtained from an assumption that creep fracture takes place when the longest crack reaches a critical length. The observed and predicted scatter of the life is fairly small for the specimens tested.

\section{INTRODUCTION}

In designing mechanical components for high temperature applications, the engineer must consider the failure mechanism at such temperature. Accumulation of creep damage often causes failure at high temperature. The creep damage usually consists of multiple cracks or cavities. For creep life prediction, it is necessary to evaluate the damage accumulation based on the synthesis of crack growth and/or cavity growth.

Creep fracture mechanisms were experimentally investigated in detail using 304 stainless steel smooth specimen in previous works (refs. 1 to 4 ). Observations revealed that: (1) cracks continuously initiated at the surface from the early stage of life to the final stage; (2) the cracks appear to grow randomly

* National Research Council - NASA Research Associate, on leave from Department of Engineering Science, Kyoto University, Kyoto, Japan. 
randomly owing to the effect of local microstructural inhomogeneities; and (3) crack coalescence and necking of the specimen (reduction of area) accelerated drastically the growth in the final stage of life. Eventually, the creep life is governed by the crack initiation and growth.

The existing fracture mechanics law for long creep crack growth (refs. 5 to 11) is not directly applicable to the random growth of microstructurally short cracks in creep. Few studies have been reported on the short creep crack growth (ref. 12) because of the difficulties in interpreting the randomness. The authors previously proposed a model of the microstructurally short creep crack growth (ref. 12). In the model, a random variable technique was used to deal with the distribution of crack growth data.

In this paper, the model is recast into a nondimensional form for prediction of the creep crack growth. This greatly reduces the numerical calculations required. Taking into account the continuous initiation of cracks and the fallure crack length the cumulative probability of creep life is predicted by a Monte Carlo simulation method on the basis of the nondimensional model.

\section{NOMENCLATURE}

a

$a_{C}$

af

B

C

$C_{C}$

D

$\mathrm{D}_{\mathrm{aV}}$

$d a / d t$

$(d a / d t)_{L}$ crack growth rate at a triple point (fig. I(b))

$(d a / d t)_{U}$ crack growth rate at a medium point between adjacent triple points (fig. 1(b))

$F(\bar{t}, \bar{a}) \quad$ cumulative probability of $f(\bar{t}, \bar{a})$ (probability that a crack reaches length $\bar{a}$ before $\bar{t}$ )

$f(\bar{t}, \bar{a})$ probability density function of a time $\bar{t}$ at the instant a crack reaches length $\bar{a}$ 


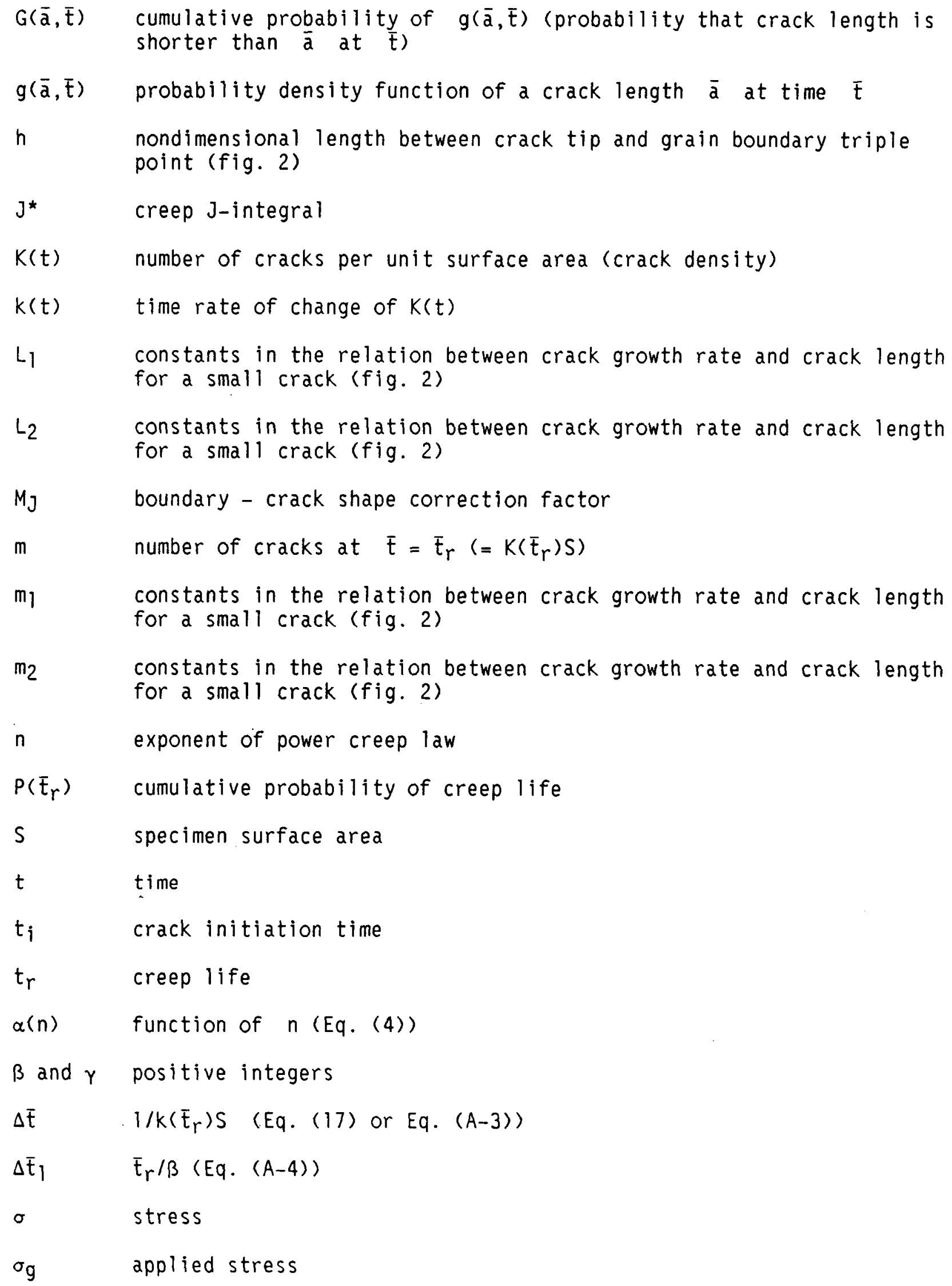


$\Phi(\bar{a}, \bar{t}) \quad$ cumulative probability of a crack length $\bar{a}$ for multiple cracks case at a time $\bar{t}$

Note: bar over variables indiates nondimensional form.

\section{SMALL CRACK GROWTH MODEL}

Figures $1(a)$ and (b) show schematic growth curves and growth rate of microstructurally short cracks initiated on the surface of a smooth specimen of 304 stainless steel under creep conditions (ref. 3 ). The characteristics of the crack growth are summarized as follows.

(1) Cracks initiate at grain boundary triple points or carbide precipitates and grow at high rates along grain boundaries but decelerate as they approach triple points or sharp bends of grain boundaries.

(2) The relation between crack growth rate and crack length is greatly dependent on individual cracks. Fluctuation in crack growth rate is large for cracks smaller than a few multiples of the grain size, $a_{c}$.

(3) The degree of fluctuation diminishes as the crack length becomes longer and blends into the scatter band for "long-crack" behavior.

A stochastic model of microstructurally short crack growth was proposed based on the experimental results in a previous paper (ref. 12). The model is summarized briefly as follows.

(1) The crack length, a, and the grain boundary length between two adjacent triple points, $D$, are the projected lengths on the plane perpendicular to the applied stress axis.

(2) The grain boundary length between two adjacent triple points, $D$, is a random variable with a normal distribution.

(3) The intergranular crack growth rate alternates between an upper and a lower peak depending on the location of crack tip as shown in figures $l(b)$ and 2 .

(4) The upper and lower peaks of the crack growth rate are modeled by random variables of logarithmic normal distributions. Their medians and 90 percent confidence bounds are listed in table I. This procedure gives reasonable crack growth data as compared with the experimental curves (ref. 12). length.

(5) The crack growth rate for a long crack is proportional to the crack

$$
\frac{d a}{d t}=C a
$$

(6) The crack growth rate between grain boundary triple points is given by the equations shown in figure 2 . 
The creep crack growth rate, da/dt, has a good correlation with a creep $J$-integral ( $C^{\star}$-parameter or modified J-integral), J* (refs. 5 to 11 ). For many materials, da/dt is proportional to $J^{*}$.

$$
\frac{d a}{d t}=C_{c} J^{*}
$$

where $C_{c}$ is a material constant (ref. 13). $J^{*}$ for a finite crack in an infinite plate is evaluated by (refs. 1 and 14)

$$
\begin{gathered}
J^{*}=M_{J} \alpha(n) B \sigma_{g}^{n+1} \alpha \\
\alpha(n)=3.85 \frac{(n-1)}{\sqrt{n}}+\frac{\pi}{n}
\end{gathered}
$$

where $M_{j}$ is the boundary - crack shape correction factor, $\sigma_{g}$ is the applied stress, and $B$ and $n$ are the coefficient and the exponent of creep power law (Norton's law), respectively. Substituting equation (3) into equation (2), we obtain

$$
\begin{aligned}
\frac{d a}{d t} & =C_{C} M_{J} \alpha(n) B \sigma_{g}^{n+1} \alpha \\
& =C a .
\end{aligned}
$$

The crack length, $a$, the time, $t$, and the stress, $\sigma$, are nondimensionalized as follows,

$$
\begin{gathered}
\bar{a}=\frac{a}{D_{a v}} \\
\bar{t}=C_{c} \sigma_{g} B \sigma_{g}^{n} t \\
\bar{\sigma}=C_{c} \sigma=C_{c} \sigma_{g}\left(\frac{\sigma}{\sigma_{g}}\right)
\end{gathered}
$$

where $D_{a v}$ is the average of the grain boundary length between two adjacent triple points. On the basis of equations (6) to ( 8 ), the relation between the nondimensional crack growth rate, $d \bar{a} / d \bar{t}$, and the nondimensional creep J-integral, $\bar{j}^{*}$, gives

$$
\frac{d \bar{a}}{d \bar{t}}=\bar{c} \bar{a}
$$

where

$$
\tau=M_{J} \alpha(n) .
$$


It should be noted that the nondimensional crack growth law is independent of the applied stress. The random variables used for the upper and lower crack growth rates are listed in table $I$ while the normalized variables are listed in table II. We are also able to normalize the quantities, $D, h, m_{1}, L_{1}, m_{2}$, and $L_{2}$ shown in figure 2. Therefore, any of the results can be derived from the nondimensional equations. Since the results are independent of the applied stress, both of the probabilities of $G(\bar{a}, \bar{t})$ and $F(\bar{t}, \bar{a})$ at any stress and at any time (to be described in the following section) can be expressed by the nondimensional analyses. Results can be converted back into the dimensional form through equations (6) to (8).

\section{PROBABILITY OF CRACK GROWTH}

The crack growth model is stochastic so that the growth curve has a probabilistic distribution as shown schematically in figure 3 . $g(\bar{a}, \bar{t})$ is a probability density function of crack length at a time $\bar{t}$ after crack initiation, and $f(\bar{t}, \bar{a})$ is a probability density function of time at the instant a crack reaches length $\vec{a}$. Their cumulative probabilities are represented by $G(\bar{a}, \bar{t})$ and $F(\bar{t}, \bar{a})$. G was partially discussed in the previous work (ref. 12), however, $F$ is introduced and discussed here for the first time.

$G(\bar{a}, \bar{t})$ and $F(\bar{t}, \bar{a})$ are numerically given by the following procedure (Monte Carlo method) as shown in figure 4 on the basis of the model:

(1) Generate random numbers.

(2) Determine random variables $\bar{D},(d \bar{a} / d \bar{t})_{U}$ and $(d \bar{a} / d \bar{t})_{L}$.

(3) Calculate the $\bar{\alpha}-\bar{E}$ relation for a crack.

(4) Repeat 1 to 3 and get the $\bar{a}-\bar{t}$ relations for many cracks.

Figure 5 shows the change of $G(\bar{a}, \bar{t})$ calculated by a simulation of 300 cracks. The constants used in the simulation are those derived from the creep behavior of 304 stainless steel at $923 \mathrm{~K}$ (refs. 2, 11, and 12) and are listed in table III. The convergence of simulation results was confirmed by a preliminary calcuilation except at the two extremes where $G(\bar{a}, E)$ is nearly equal to zero or one (ref. 12). $G(\bar{a}, \bar{t})$ can be physically interpreted as the probability that a crack length is shorter than $\bar{a}$ at time $\bar{E}$. It becomes clear from figure 5 that the distributions change very little within the region $G(\bar{a}, \bar{t})<$ 0.5 , while they are strongly depending on $\bar{t}$ for $G(\bar{a}, \bar{t})>0.8$. This result suggests that the first grain boundary triple point has a high probability of blocking the crack growth and that the crack grows faster once it passes through the triple point. Similar tendencies were found in experiments (refs. 1 and 3 ).

Figure 6 shows $F(\bar{t}, \bar{a})$ which is obtained by the simulation of 30000 cracks in order to clarify the distribution near $F(\bar{t}, \bar{a})=0$. $F(\bar{t}, \bar{a})$ is the probability that the time when a crack length reaches $\bar{a}$ is shorter than $\bar{t}$. The distribution shows that there is a difference in the shorter $\bar{t}$ region, while in the longer $\bar{t}$ region differences disappear. The difference at the shorter $\bar{t}$ affects the probability of creep life. 


\section{CRACK LENGTH DISTRIBUTION}

Multiple cracks generally initiate continuously on the surface of a smooth specimen during the entire creep test. The actual distribution of crack lengths observed at a given time $\bar{t}$ is brought on not only by the distribution of crack growth rates but also by the difference in the crack initiation time. $G(\bar{a}, \bar{t})$ obtained in the previous section is the cumulative probability of crack length at $\bar{t}$ after the initiation of a single crack (or that for multiple cracks initiated at the same time). Therefore, it is necessary for the prediction of the actual crack length distribution to be coupled with the distribution for crack initiation.

The cumulative probability for an actual crack distribution, $\Phi(\bar{\alpha}, \bar{t})$, at a time $\bar{E}$ is predicted by the following equation:

$$
\Phi(\bar{\alpha}, \bar{t})=\int_{0}^{\bar{t}} G\left(\bar{\alpha}, \bar{t}-\bar{t}_{j}\right) k\left(\bar{t}_{j}\right) d \bar{t}_{i} / k(\bar{t})
$$

where $K(\bar{t})$ is the number of cracks per unit surface area (i.e., crack density) at time $\bar{t}, \bar{t}_{j}$ is a nondimensional crack initiation time, and $k(\bar{t})$ is the time rate of change of $K(\bar{t})$. $\Phi(\bar{a}, \bar{t})$ can be interpreted as the probabil$i$ ty that the crack lengths are shorter than $\bar{\alpha}$ at a time $\bar{a}$. The numer of cracks initiated from time $\bar{t}$ to $\bar{t}+d \bar{t}$ is given as

$$
d K(\bar{t})=\frac{d K(\bar{t})}{d \bar{t}} d \bar{t}=K(\bar{t}) d \bar{t} .
$$

Experimental observations have shown that $K(E)$ was nearly proportional to $\bar{t}$ for conditions of creep (refs. $I$ and 2 ). Thus, $k(E)$ is constant and equation (11) can be written in the form

$$
\Phi(\bar{a}, \bar{t})=\frac{1}{\bar{t}} \int_{0}^{\bar{t}} G\left(\bar{a}, \bar{t}-\bar{t}_{i}\right) d \bar{t}_{j} .
$$

The lines shown in figure 7 are the predicted probabilities of crack length for a smooth specimen of 304 stainless steel at $923 \mathrm{~K}$. Figures $7(a)$ and (b) are the probabilities at the medium creep life and near the end of creep life, respectively. The figures also include the actual distribution obtained from a creep test in air (ref. 2). The predictions agree well with the test results. Similar successful results are obtained at other times $\bar{t}$ in air as well as the experimental results (ref. 2) in vacuum.

\section{CREEP LIFE OF SMOOTH SPECIMEN}

Creep tests of 304 stainless steel revealed that the creep failure of smooth specimens took place soon after the longest crack reached a critical crack length, af (ref. 2). Crack coalescence and tertiary creep (reduction of area) brought on the drastic acceleration of crack growth and the unstable fracture. For the tests conducted in the previous work (ref. 2), the value 
of af was about $0.15 \mathrm{~mm}$. This implies that the growth of microstructurally short cracks govern the majority of the creep fracture.

Assuming a critical crack length for rupture, the cumulative probability of creep life, $P\left(\bar{t}_{r}\right)$, becomes equivalent to the probability that the longest crack reaches the length $\bar{a}_{f}$. Here, multiple crack initiations must be taken into consideration. The derivation of $P\left(\bar{t}_{r}\right)$ from $F(\bar{E}, \bar{a})$ is described as follows. The probability that a crack initiated at time $\bar{t}_{j}$ does not reach $\bar{a}_{f}$ at time $\bar{t}$ is given by $\left[1-F\left(\bar{t}-\bar{t}_{i}, \bar{a}_{f}\right)\right]$. Then,

m

$\prod\left\{1-F\left(\bar{t}-\bar{t}_{j}, \bar{a}_{f}\right)\right\}$ is the probability that none of the cracks initiated at $j=1$

$\bar{t}_{1}, \bar{t}_{2}, \ldots \bar{t}_{m}$, reach $\bar{a}_{f}$ at $\bar{t} . P\left(\bar{t}_{r}\right)$, therefore, is given by

$$
\begin{gathered}
P\left(\bar{t}_{r}\right)=1-\prod_{j=1}^{m}\left\{1-F\left(\bar{t}_{f}-\bar{t}_{j}, \bar{a}_{f}\right)\right\} \\
m=k\left(\bar{t}_{r}\right) s
\end{gathered}
$$

Again, assuming $k(\bar{t})$ is constant, equation (14) is converted into

$$
\begin{gathered}
P\left(\bar{t}_{r}\right)=1-\prod_{j=1}^{m}\left\{1-F\left((m-j) \cdot \Delta t, \bar{a}_{f}\right)\right\} \\
\Delta t=\frac{1}{k\left(E_{r}\right) s}
\end{gathered}
$$

where $S$ is the specimen surface area.

$P\left(\bar{t}_{r}\right)$ is sensitive to the distribution near $F\left(\bar{E}, \bar{a}_{f}\right) \approx 0$, as shown in figure 8 wherein the detailed distribution is given by the simulation of 150000 cracks. $P\left(E_{r}\right)$ shown in figure 9 is obtained from the distribution of figure 8 and equation (16). To simplify the solution of equation (16), an approximate estimation is used as described in the appendix. Figure 9 reveals that as the number of cracks, $K\left(\bar{t}_{r}\right) S$, increases, the creep life decreases and the scatter becomes smaller. In other words, the specimen surface area available for cracking will affect the creep life. Figure 10 shows the relationship between the nondimensional creep life and the number of cracks at $P\left(\bar{t}_{r}\right)=0.1,0.5$, and 0.9. The life changes considerably in the range of $K\left(E_{r}\right) S<3000$, but little in the range of $5000 \leq k\left(E_{\zeta}\right) S \leq 10000$. In the creep tests carried out previously, $K\left(\bar{t}_{r}\right)$ is about $20 \mathrm{~mm}^{-2}$ independent of the applied stress (ref. 2 ). Hence, the scale of $S$ 'can be given and is shown on the upper side of figure 10. The real time scale at several stresses are also drawn at the right side of the same figure. The scatter of creep life is very small in the range of $250 \mathrm{~mm}^{2} \leq S \leq 500 \mathrm{~mm}^{2}$. 
$S$ is equal to $320 \mathrm{~mm}^{2}$ for the tested plate specimen of 304 stainless steel (width, thickness, and gauge length are 12,4 , and $10 \mathrm{~mm}$, respectively) so that $K\left(\bar{t}_{r}\right) S$ becomes 6400 . The band in figure 11 shows the relationship between applied stress and predicted creep life for $0.1 \leq P\left(E_{r}\right) \leq 0.9$ and $K\left(E_{r}\right) S=6400$. Also shown in figure 11 are the actual experimental results of creep rupture data (refs. 2 and 15). The predictions show good agreement with the data.

The growth of surface cracks governs creep fracture in this relatively short time and high stress regime. However, it is expected that internal cracking plays an important role in the fracture process at lower stresses and longer times. Life prediction at lower stress may have to be modified to account for internal initiation and crack growth.

\section{CONCLUSION}

A nondimensional model of microstructually small crack for creep life prediction is proposed. The probability distributions of crack lengths and creep life are predicted based on the model. The results obtained are summarized as follows.

1. The stochastic model of small crack growth is generalized. In the model, the scatter of crack growth rate owing to microstructual inhomogeneity is represented by means of random variables. The nondimensional model gives a general probability of crack growth independent of applied stress.

2. The cumulative probability of crack length at a time $\bar{t}, G(\bar{a}, \bar{t})$, and the cumulative probability of time when a crack reaches length $\bar{a}, F(\bar{t}, \bar{a})$, are calculated by means of the Monte Carlo simulation method.

3. Taking into account the multiple crack initiations, the cumulative probability of crack length for the multiple cracks, $\Phi(\bar{a}, \bar{t})$, is obtained from $G(\bar{a}, \bar{t})$. The predictions agree well with the actual distribution of crack lengths observed on a specimen of 304 stainless steel tested in creep at $923 \mathrm{~K}$.

4. The cumulative probability of creep life, $P\left(E_{r}\right)$, is derived by assuming that the longest crack is responsible for the ultimate fracture. Predictions and experimental results are in good agreement. 


\section{APPENDIX A}

To simplify the solution of equation (16), an approximation is discussed in this section.

The following relation is given because $(1-F(\bar{t}, \bar{a}))$ is a nonincreasing function against $\bar{t}$.

$$
\begin{gathered}
\prod_{j=0}^{\beta-1}\left\{1-F\left((\beta-j) \Delta \bar{t}_{1}, \bar{a}_{f}\right)\right\}^{\gamma} \leqq \prod_{j=1}^{m}\left\{1-F\left((m-j) \Delta \bar{t}, \bar{a}_{f}\right)\right\} \\
\leqq \\
\equiv \prod_{j=1}\left\{1-F\left((\beta-j) \Delta \bar{t}_{1}, \bar{a}_{f}\right)\right\}^{\gamma} \\
\beta \cdot \gamma=m \\
\Delta \bar{t}^{\prime}=\frac{\bar{t}_{r}}{m} \\
\Delta \bar{t}_{1}=\frac{\bar{t}_{r}}{\beta}
\end{gathered}
$$

Equation $(A-1)$ is reduced to

$$
\begin{aligned}
\left\{1-F\left(\bar{t}_{r}, \bar{a}_{f}\right)\right\}^{Y} \prod_{j=1}^{\beta}\left\{1-F\left((\beta-j) \Delta \bar{t}_{1}, \bar{a}_{f}\right)\right\}^{Y} & \leqq \prod_{j=1}^{m}\left\{1-F\left((m-j) \Delta \bar{t}_{,} \bar{a}_{f}\right)\right\} \\
& \leqq \prod_{j=1}^{\beta}\left\{1-F\left((\beta-j) \Delta \bar{t}_{1}, \bar{a}_{f}\right)\right\}
\end{aligned}
$$

If $\beta$ and $Y$ are chosen as $\left\{1-F\left(\bar{t}_{r}, \bar{a}\right)\right\}^{Y}$ is nearly equal to one, the following relation is given.

$$
\prod_{j=1}^{\beta}\left\{1-F\left((\beta-j) \Delta \bar{t}_{1}, \bar{a}_{f}\right)\right\}^{Y}
$$

$$
\approx \prod_{j=1}^{m}\left\{1-F\left((m-j) \Delta \bar{t}, \bar{a}_{f}\right)\right\}=P\left(\bar{t}_{r}\right)
$$


In this study, $P\left(E_{r}\right)$ is calculated by choosing $\beta$ and $\gamma$ as $0.9 \leq$ $\left\{1-F\left(\bar{t}_{r}, \bar{a}\right)\right\}^{Y} \leq 1$. 


\section{REFERENCES}

1. Ohtani, R., Okuno, M., and Shimizu, R., "Microcrack Growth in Grain Boundaries at the Surface of Smooth Specimen of 316 Stainless Steel in High Temperature Creep," (in Japanese), Zairyo (Journal of the Society of Materials Science, Japan), Vol. 31, No. 344, May 1982, pp. 505-509.

2. Ohtani, R., and Nakayama, S., "Growth and Distribution of Microcracks at the Surface of Smooth Specimen of 304 Stainless Steel in Creep and Effect of High Temperature Oxidation," (in Japanese), Zairyo (Journal of the Society of Materials Science, Japan), Vol. 32, No. 357, June 1983, pp. 635-639.

3. Ohtani, R., Nakayama, S., and Taira, T., "Applicability of Creep J-integral to Microcrack Propagation of Creep in 304 Stainless Steel," (in Japanese), Zairyo (Journal of the Society of Materials Science, Japan), Vol. 33, No. 368, May 1984, pp. 590-595.

4. Ohtani, R., and Kinami, T., "Nucleation, Propagation and Distribution of Creep Microcracks in 304 Stainless Steel," International Conference on Creep, JSME, Tokyo, 1986, pp. 167-172.

5. Ohji, K., Ogura, K., and Kubo, S., "Creep Stress Analysis of a Notched Body Under Longitudinal Shear and Its Application to Crack Propagation Problems," Mechanical Behavior of Materials, Vol. 1, Society of Materials Science, Kyoto, Japan, 1974, pp. 455-466.

6. Landes, J.D., and Begley, J.A., "A Fracture Mechanics Approach to Creep Crack Growth," Mechanics of Crack Growth, ASTM STP-590, ASTM, Philadelphia, 1976, pp. 128-148.

7. Nikbin, K.M., Webster, G.A., and Turner, C.E., "Relevance of Nonlinear Fracture Mechanics to Creep Cracking," Cracks and Fracture, ASTM STP-601, ASTM, Philadelphia, 1976, pp. 47-62.

8. Harper, M.P., and Ellison, E.G., "The Use of the $C^{*}$ Parameter in Predicting Creep Crack Propagation Rates," Journal of Strain Analysis for Engineering Design; Vol. 12, No. 3, July 1977, pp. 167-179.

9. Sadananda, K., and Shahinian, P., "Creep Crack Growth in Alloy 718," Metallurgical Transactions A., Vol. 8, No. 3, Mar. 1977, pp. 439-449.

10. Koterazawa, R., and Mori, T., "Applicability of Fracture Mechanics Parameters to Crack Propagation Under Creep Condition," Journal of Engineering Materials and Technology, Vol. 99, No. 4, Oct. 1977, pp. 297-305.

11. Taira, S., Ontani, R., and Kitamura, T., "Application of J-Integral to High-Temperature Crack Propagation, Part I - Creep Crack Propagation," Journal of Engineering Materials and Technology, Vol. 101, No. 2, Apr. 1979, pp. 154-161.

12. Kitamura, T., and Ohtani, R., "Numerical Simulation of Microstructurally Short Crack Propagation in Creep," (in Japanese) Nippon Kikai Gakkai Ronbunshu, (Transactions JSME), Vol. 53, No. 490, June 1987, pp. 1064-1070. 
13. Ohtani, R., Kitamura, T., Nitta, A., and Kuwabara, K., "High-Temperature LCF Crack Propagation and Life Laws of Smooth Specimens Derived from the Crack Propagation Laws," Symposium Low Cycle Fatigue - Directions for the Future, ASTM STP-942, ASTM, Philadelphia, to be published.

14. Shih, C.F. and Hutchinson, J.W., "Fully Plastic Solutions and Large Scale Yielding Estimates for Plane Stress Crack Problems," Journal of Engineering Materials and Technology, Vol. 98, No. 4, Oct. 1976, pp. 289-295.

15. Ohtani, R., and Taira, S., "Effects of Nonlinear Stress-Strain Rate Relation on Deformation and Fracture of Materials in Creep Range, "Journal of Engineering Materials and Technology, Vol. 101, No. 4, Oct. 1979, pp. 369-373.

TABLE I. - LOG NORMAL DISTRIBUTION OF CRACK GROWTH RATE IN THE OIMENSIONAL MODEL

\begin{tabular}{|c|c|c|c|c|}
\hline & \multicolumn{2}{|r|}{$a \geqq a_{c}$} & \multicolumn{2}{|c|}{$a<a_{c}$} \\
\hline & Median & $\begin{array}{c}\text { Upper confidence } \\
\text { limit, } \\
90 \text { percent }\end{array}$ & Median & $\begin{array}{c}\text { Upper confidence } \\
\text { limit, } \\
90 \text { percent }\end{array}$ \\
\hline $\begin{array}{l}(d a / d t)_{U} \\
(d a / d t)_{L}\end{array}$ & $\begin{array}{l}\sqrt{2} C a \\
C a / \sqrt{2}\end{array}$ & $\begin{array}{l}2 \mathrm{Ca} \\
\mathrm{Ca}\end{array}$ & $\begin{array}{l}\sqrt{2} C a\left(a / a_{c}\right)^{0.414} \\
C a_{c}\left(a / a_{c}\right)^{0.414 / \sqrt{2}}\end{array}$ & $\begin{array}{c}2 \mathrm{Ca}_{\mathrm{c}} \\
\mathrm{Ca}\end{array}$ \\
\hline
\end{tabular}

TABLE II. - LOG NORMAL DISTRIBUTION OF CRACK GROWTH RATE IN THE NONDIMENSIONAL MODEL

\begin{tabular}{|c|c|c|c|c|}
\hline & \multicolumn{2}{|r|}{$\overline{\mathrm{a}} \geqq \overline{\mathrm{a}}_{\mathrm{c}}$} & \multicolumn{2}{|c|}{$\overline{\mathrm{a}}<\overline{\mathrm{a}}_{\mathrm{c}}$} \\
\hline & Median & $\begin{array}{c}\text { Upper confidence } \\
1 \text { imit, } \\
90 \text { percent }\end{array}$ & Median & $\begin{array}{c}\text { Upper confidence } \\
\text { limit, } \\
90 \text { percent }\end{array}$ \\
\hline$(d \bar{a} / d \bar{E})_{U}$ & $\sqrt{2} \mathrm{C} \overline{\mathbf{a}}$ & $2 \bar{C} \bar{a}$ & $\sqrt{2} \overline{\mathrm{C}} \overline{\mathrm{a}}\left(\overline{\mathrm{a}} / \overline{\mathrm{a}}_{\mathrm{c}}\right)^{0.414}$ & $2 \overline{\mathrm{C}} \overline{\mathrm{a}}_{\mathrm{c}}$ \\
\hline$(d \bar{a} / d t)_{L}$ & $\bar{c} \bar{a} / \sqrt{2}$ & $\bar{c} \bar{a}$ & $\bar{c} \bar{a}_{c}\left(\bar{a} / \bar{a}_{c}\right)^{0.414} / \sqrt{2}$ & $\overline{\mathbf{C}} \overline{\mathbf{a}}$ \\
\hline
\end{tabular}

TABLE III. - CONSTANTS FOR THE CALCULATION OF CREEP IN 304 STAINLESS STEEL AT $923 \mathrm{~K}$ IN AIR

\begin{tabular}{|c|c|c|}
\hline Constant & Value & Note \\
\hline B & $1.37 \times 10^{-18}$ & \multirow{2}{*}{$\begin{array}{l}\dot{\varepsilon}_{c}=\text { Bon Norton's law } \\
\dot{\varepsilon}_{c}: \text { Creep strain rate }\left[h^{-1}\right] \\
\sigma: \text { Stress [MPa] }\end{array}$} \\
\hline$n$ & 7.1 & \\
\hline$M_{\mathrm{J}}$ & 0.51 & For semi-circular surface crack \\
\hline$a_{c}$ & $0.1 \mathrm{~mm}$ & - \\
\hline$D_{a v}$ & $0.02 \mathrm{~mm}$ & $\begin{array}{l}\text { Average of grain boundary length } \\
\text { between two adjacent triple points }\end{array}$ \\
\hline$D_{s t}$ & $0.005 \mathrm{~mm}$ & $\begin{array}{l}\text { Standard deviation of grain boundary } \\
\text { length between two adjacent triple points }\end{array}$ \\
\hline$C_{c}$ & $0.0096 \mathrm{MPa}^{-1}$ & 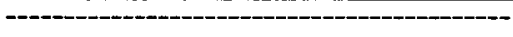 \\
\hline
\end{tabular}




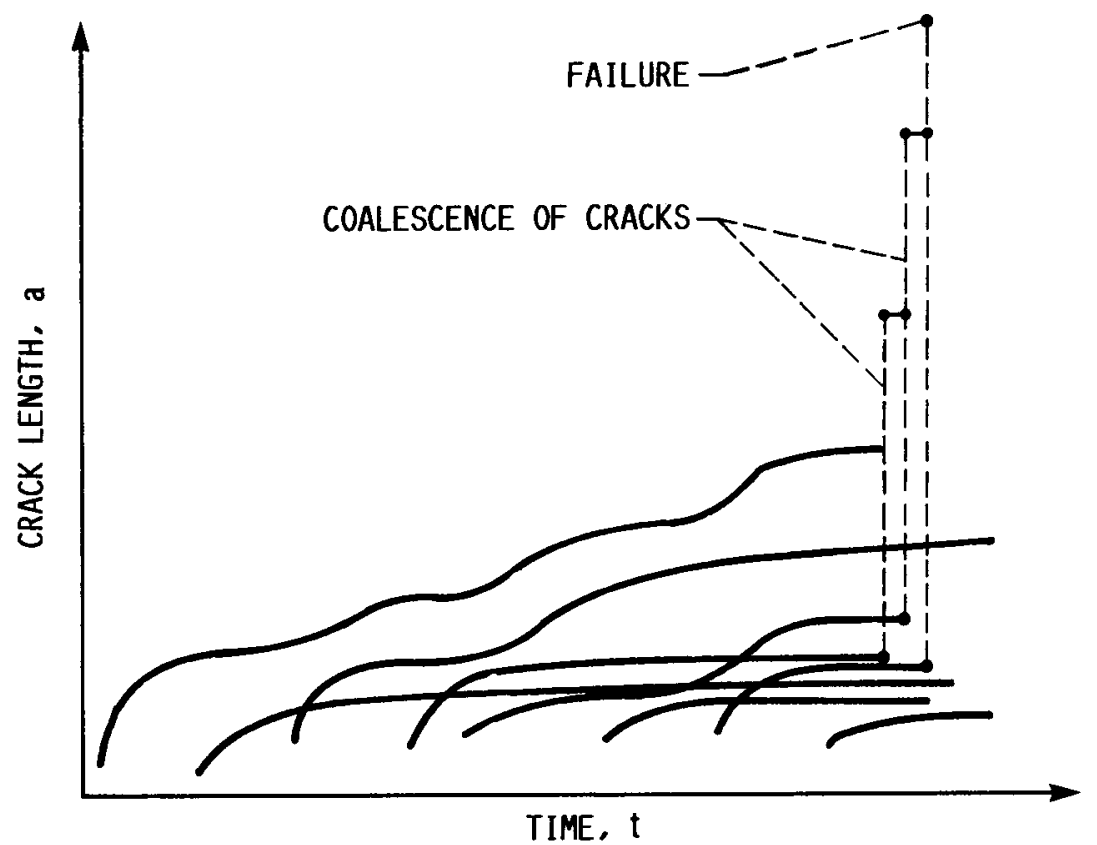

(a) SCHEMATIC DIAGRAM SHOWING GROWTH CURVES OF SMALL CRACKS INITIATED ON THE SURFACE OF A SPECIMEN.

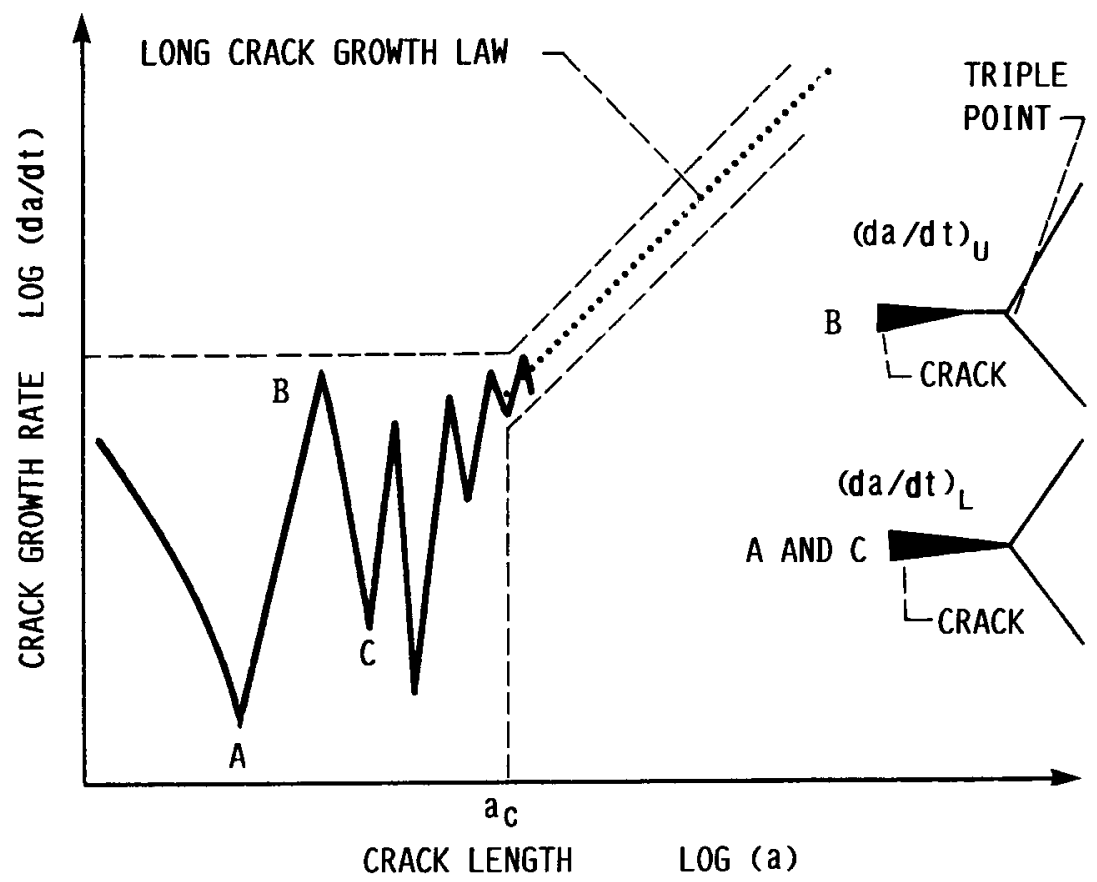

(b) SCHEMATIC DIAGRAM SHOWING RELATIONSHIP BETWEEN CRACK GROWTH RATE AND HALF CRACK LENGTH.

FIGURE 1. 


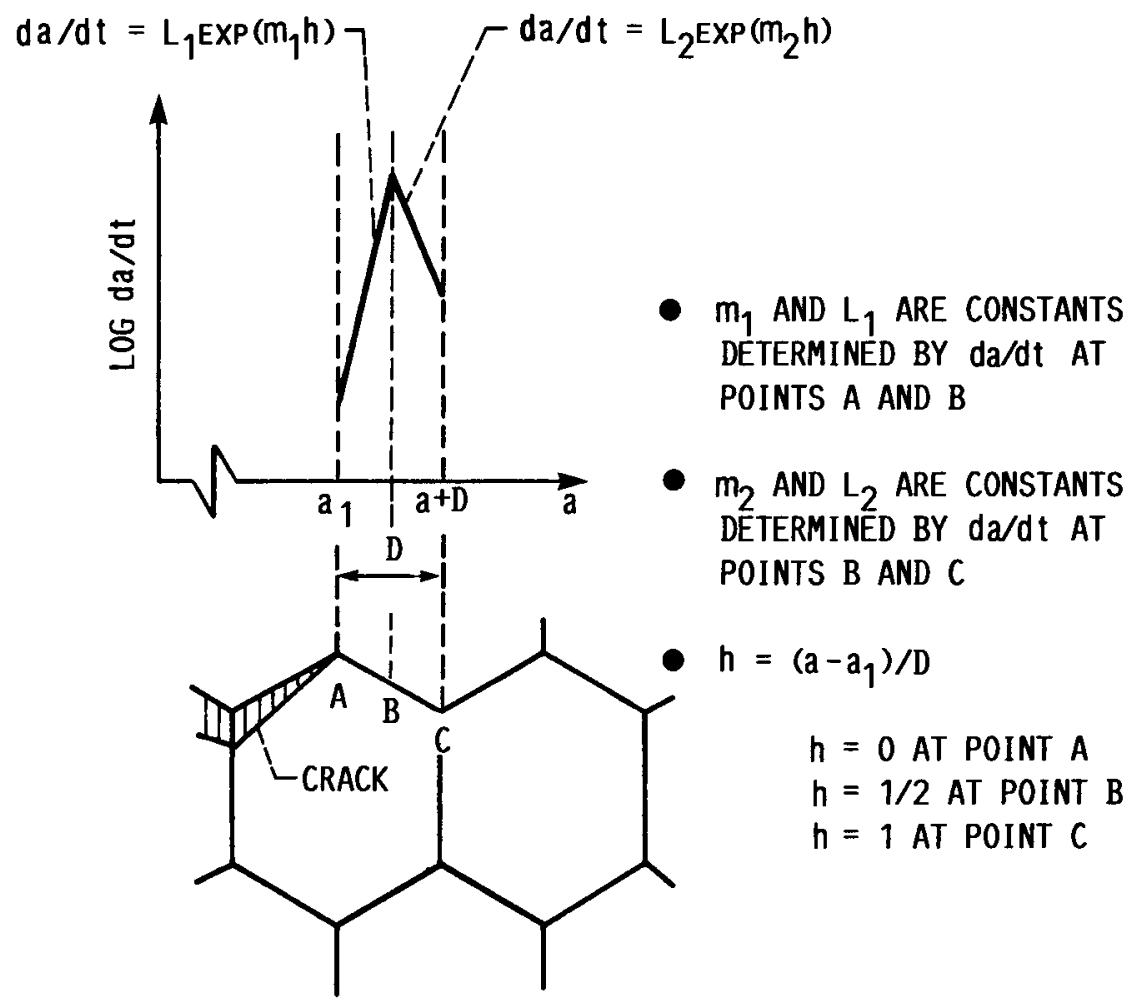

FIGURE 2. - SCHEMATIC REPRESENTATION OF CRACK GROWTH RATE IN THE MODEL.

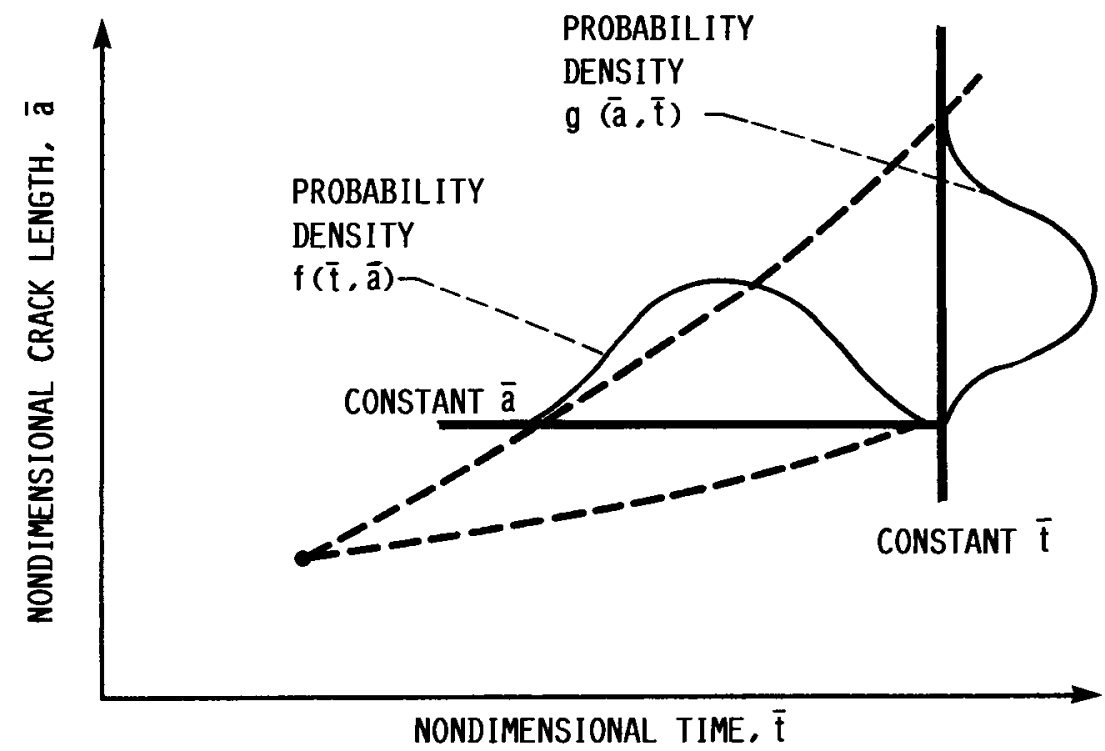

FIGURE 3. - SCHEMATIC DIAGRAM SHOWING STOCHASTIC CRACK GROWTH. 


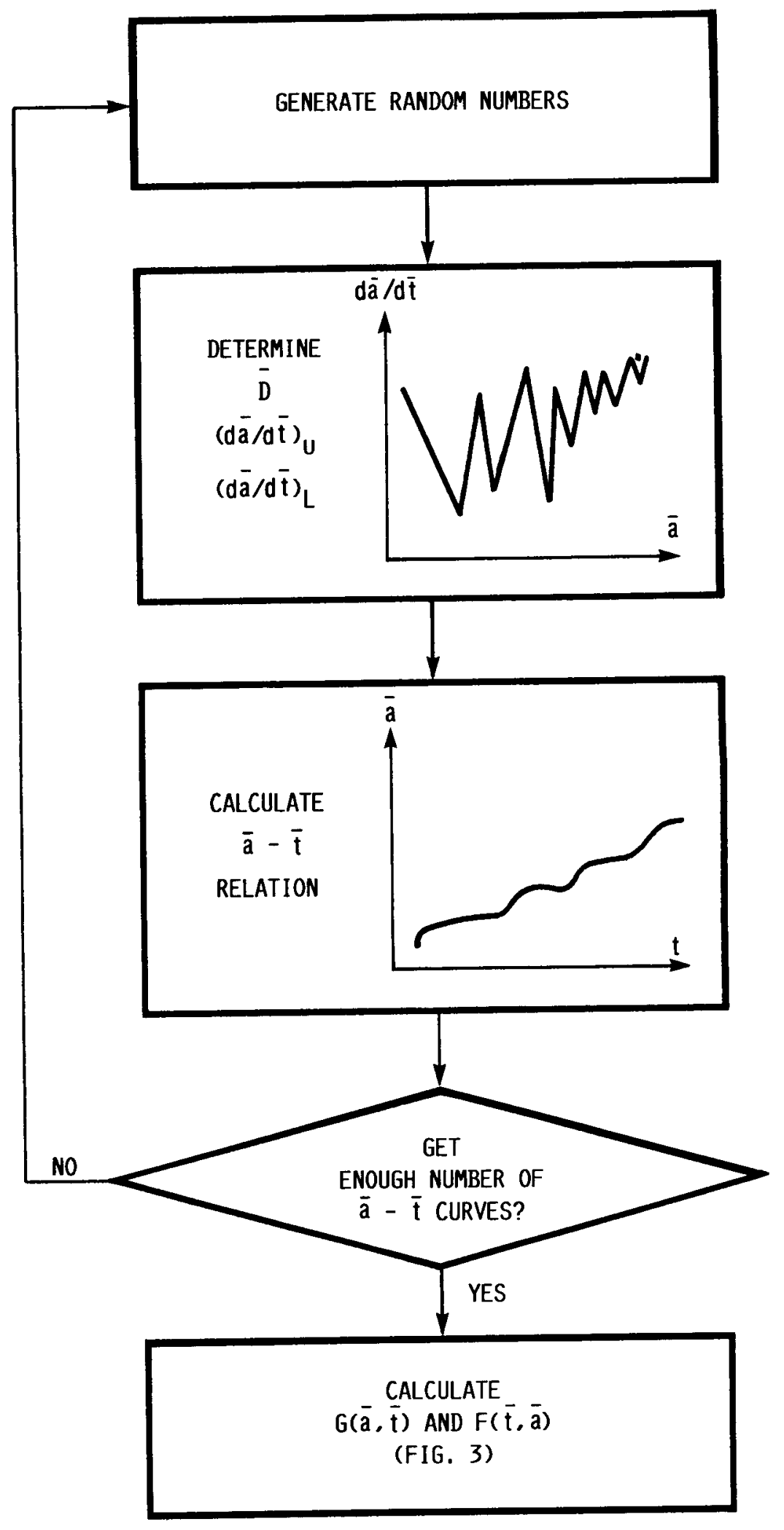

FIGURE 4. - FLOWCHART OF THE CRACK GROWTH SIMULATION. 


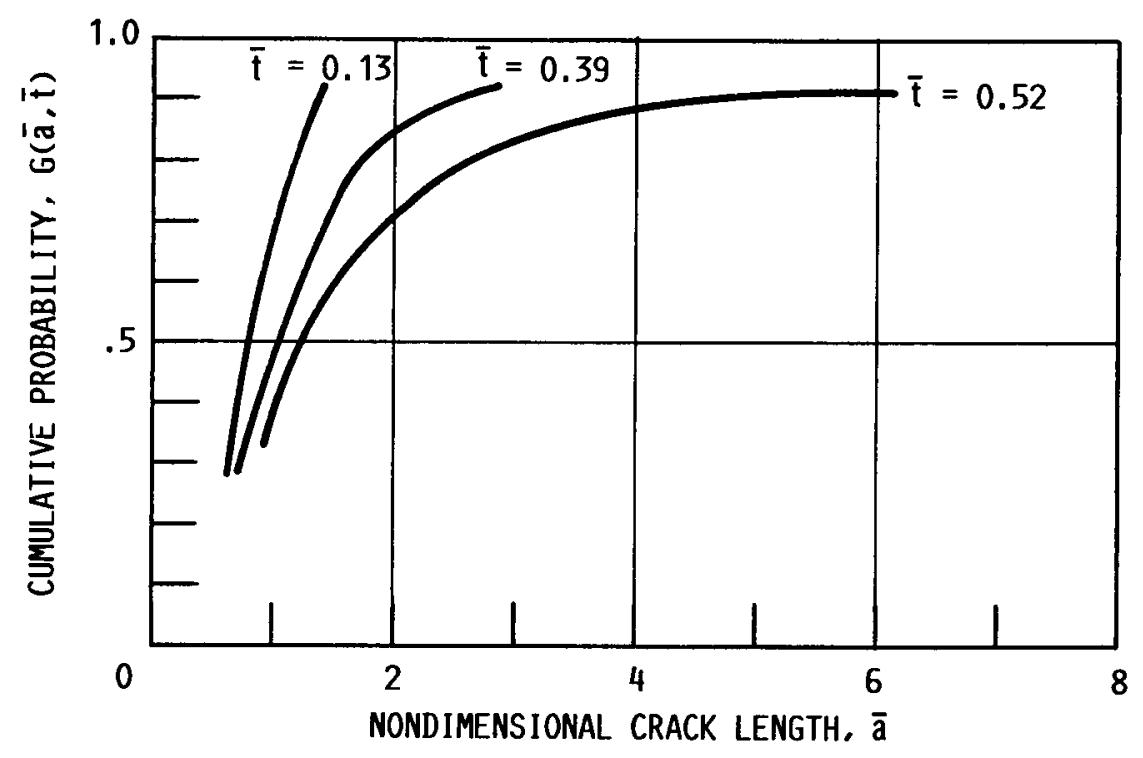

FIGURE 5. - CUMULATIVE PROBABILITY OF CRACK LENGTH AT TIME $\overline{\mathrm{t}}$ FOR A SINGLE CRACK, $G(\bar{a}, \overline{\mathrm{t}})$.

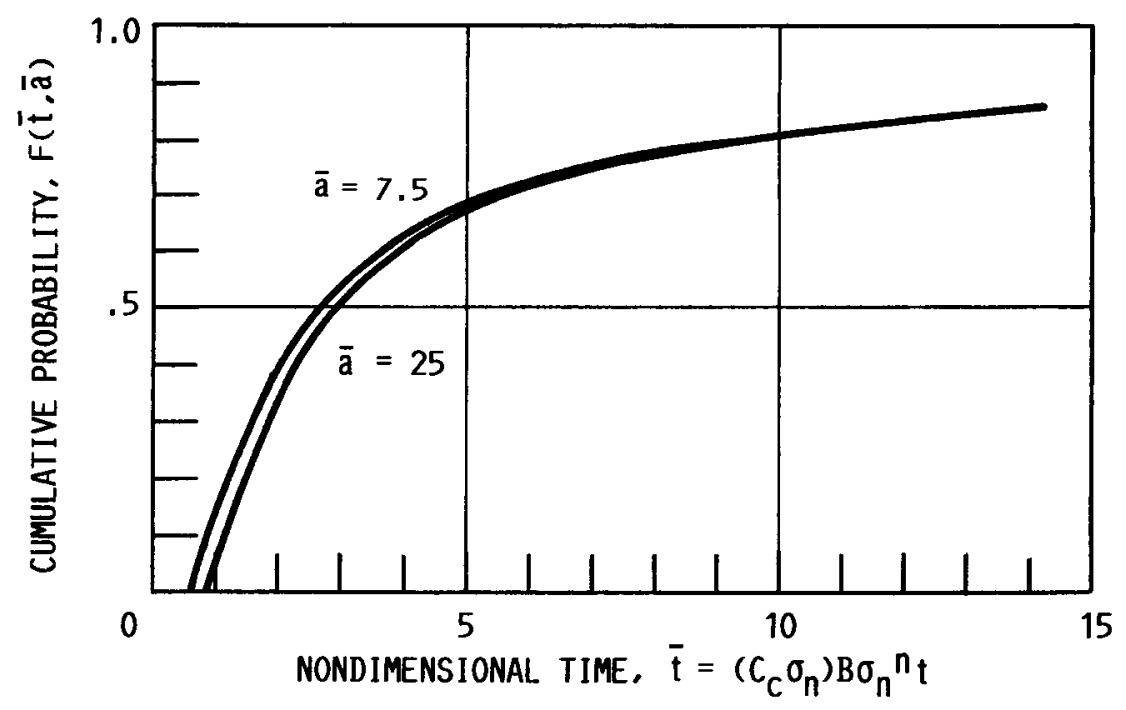

FIGURE 6. - CUMULATIVE PROBABILITY OF TIME WHEN A CRACK REACHES LENGTH $\bar{a}$ FOR A SINGLE CRACK, F $(\overline{\mathrm{t}}, \overline{\mathrm{a}})$. 


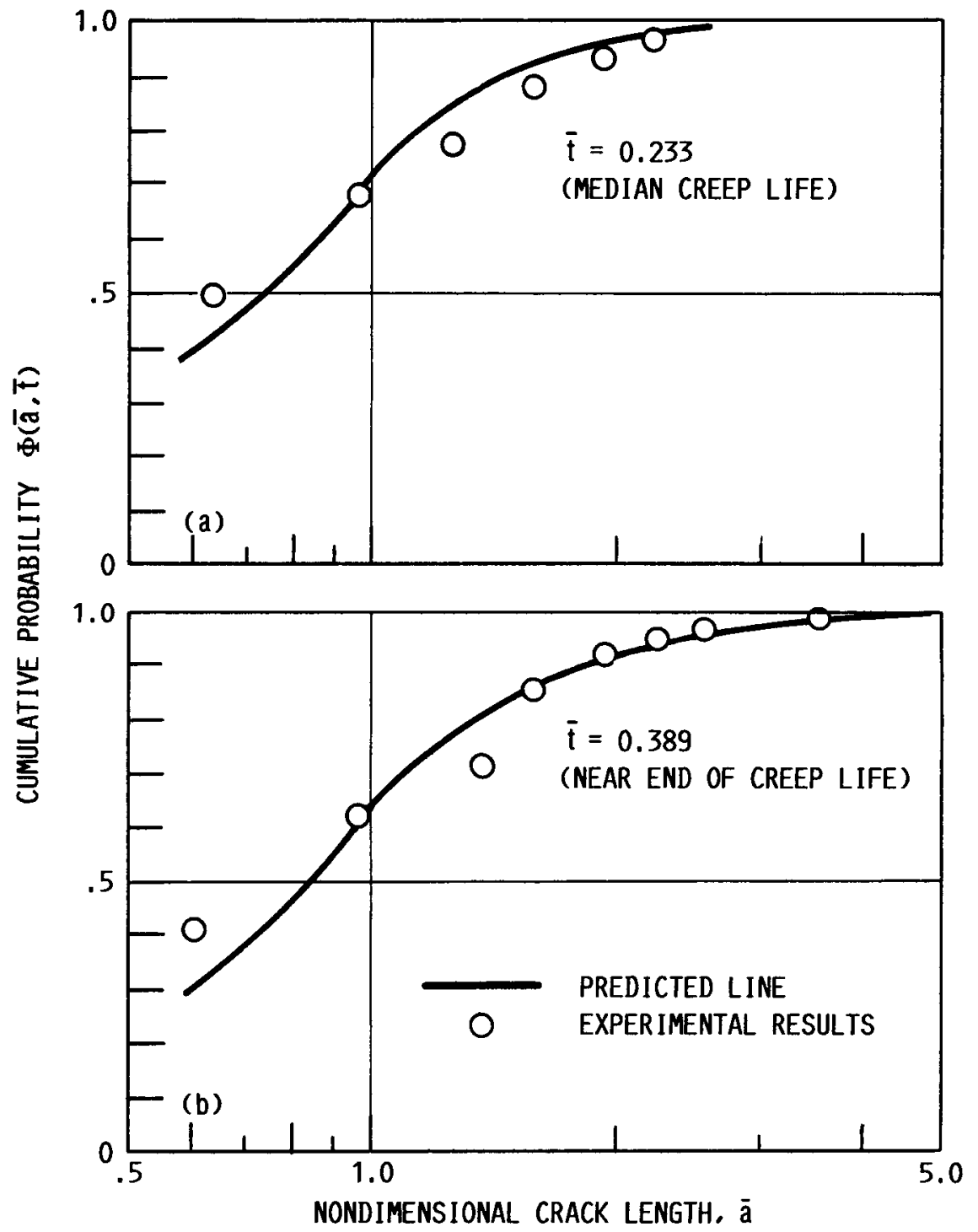

FIGURE 7. - COMPARISON OF CRACK LENGTH DISTRIBUTION BETWEEN PREDICTION AND EXPERIMENT. 


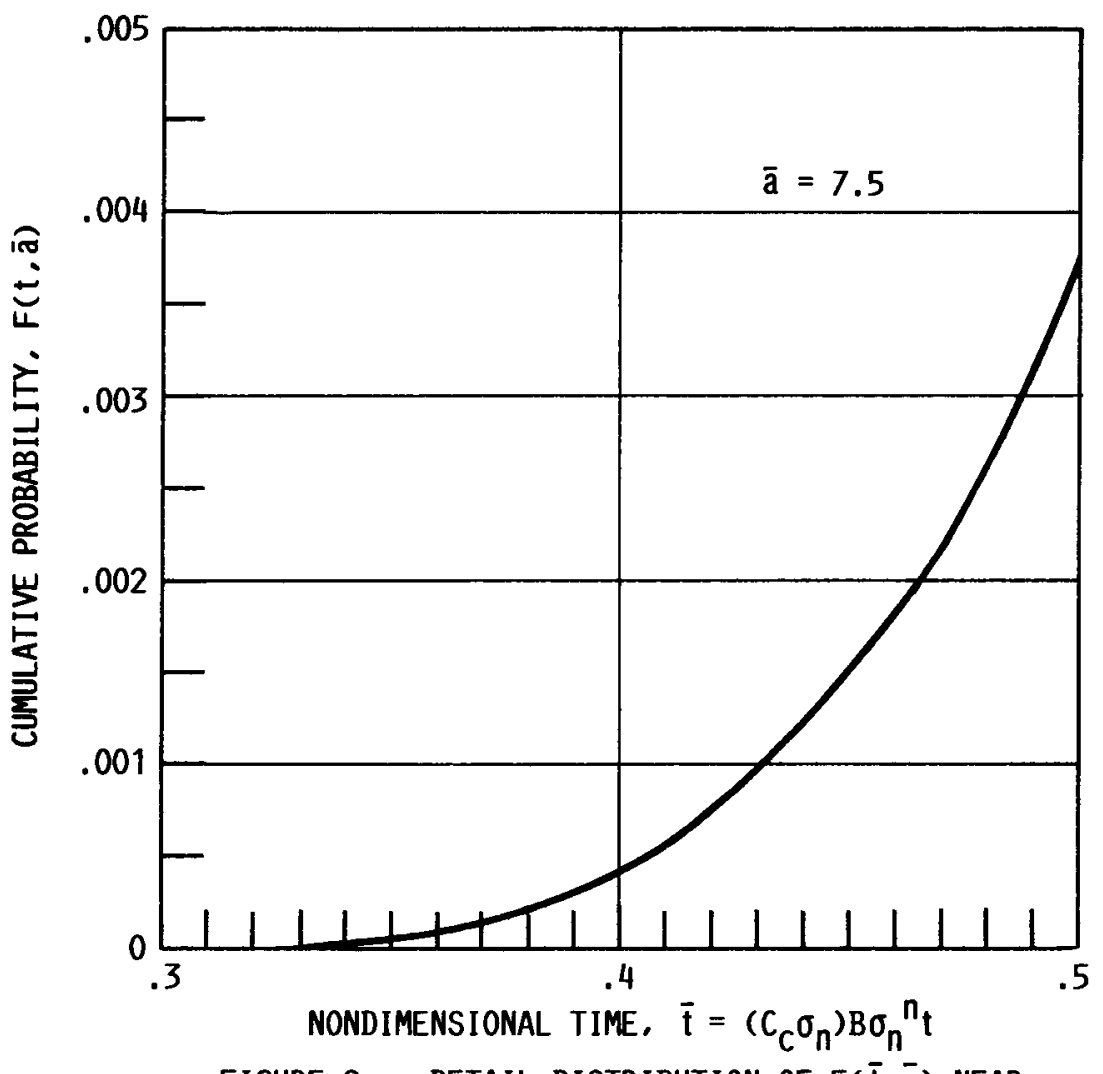

FIGURE 8. - DETAIL DISTRIBUTION OF $F(\bar{t}, \bar{a})$ NEAR $F(\bar{t}, \bar{a})=0$. 


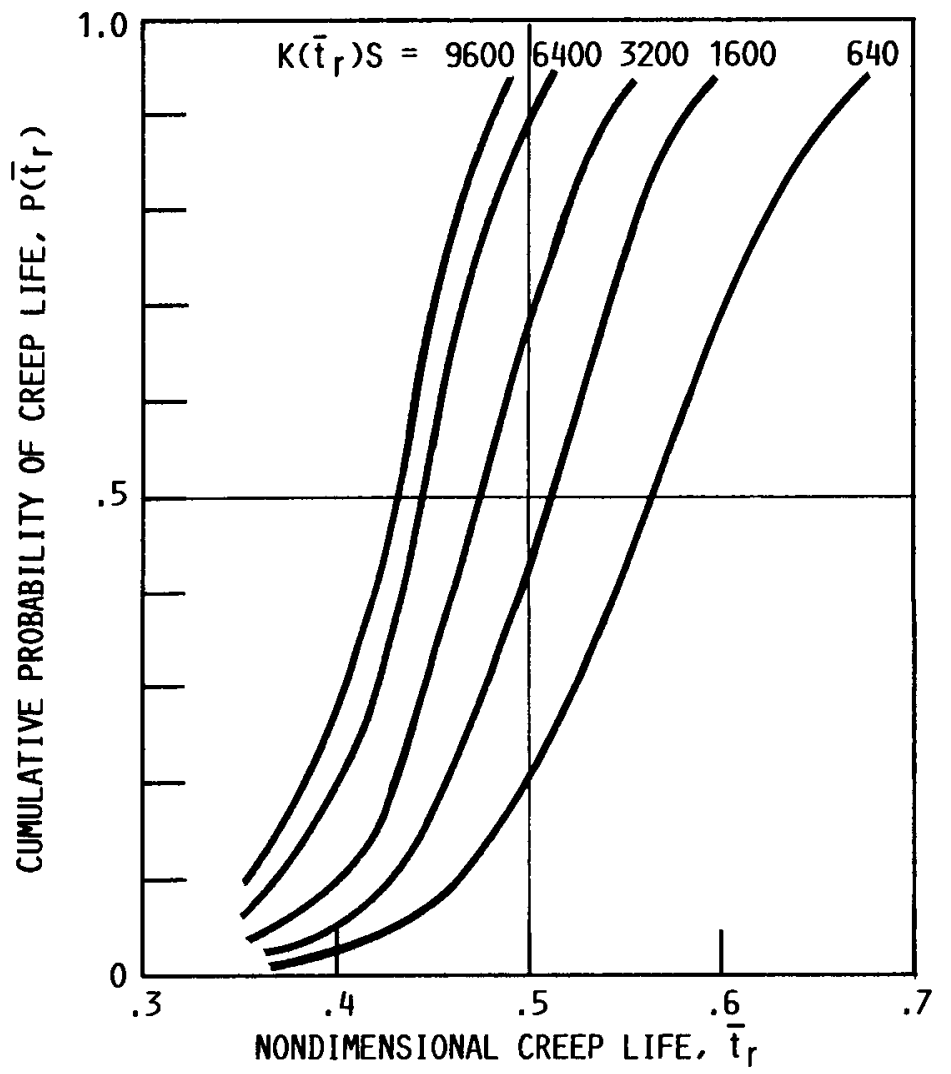

FIGURE 9. - CUMULATIVE PROBABILITY OF NONDIMENSIONAL LIFE PREDICTED BASED ON THE MODEL OF MICROSTRUCTUALLY SHORT CRACK GROWTH. 


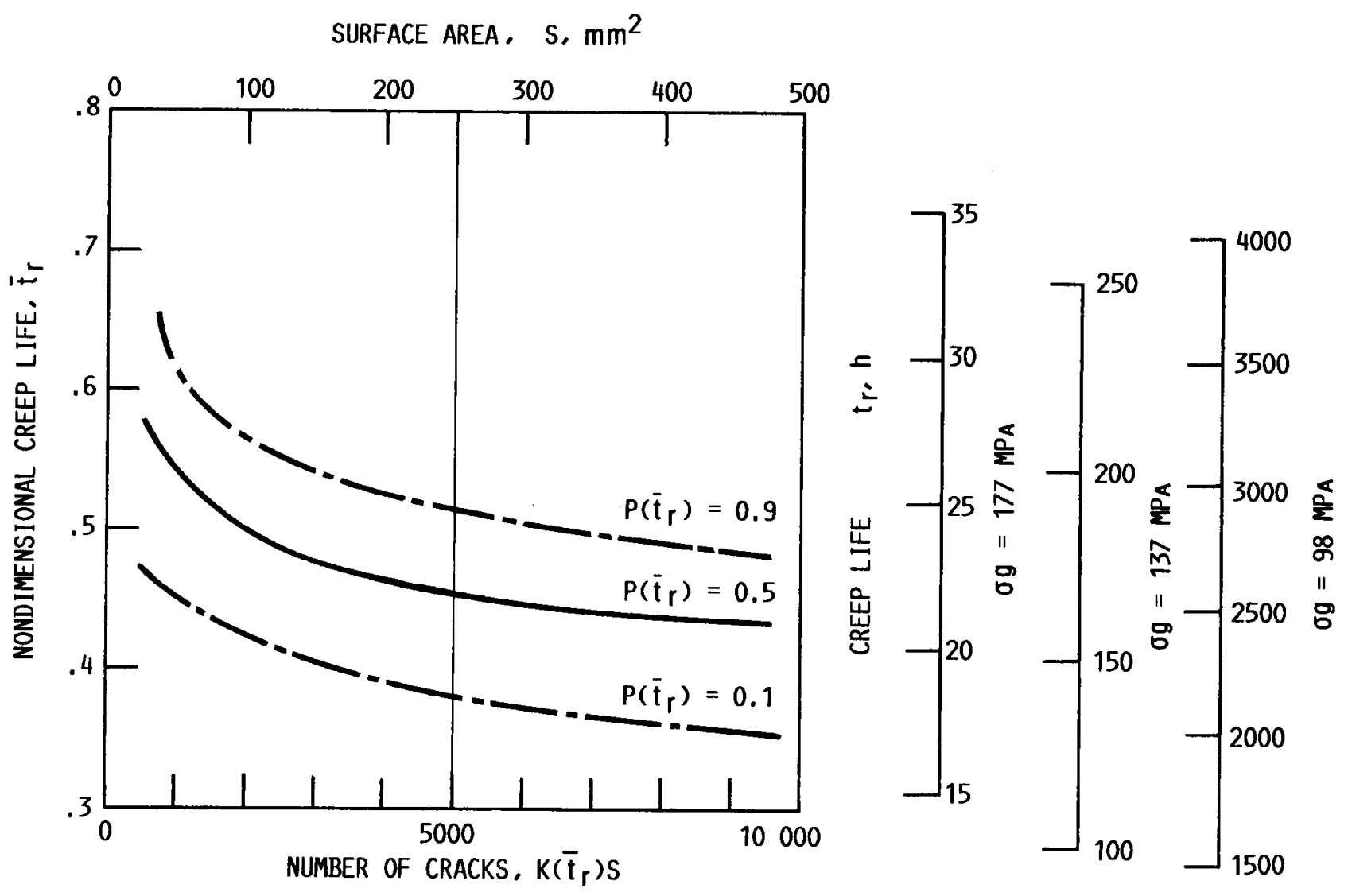

FIGURE 10. - RELATIONSHIP BETWEEN NONDIMENSIONAL CREEP LIFE AND NUMBER OF CRACKS.

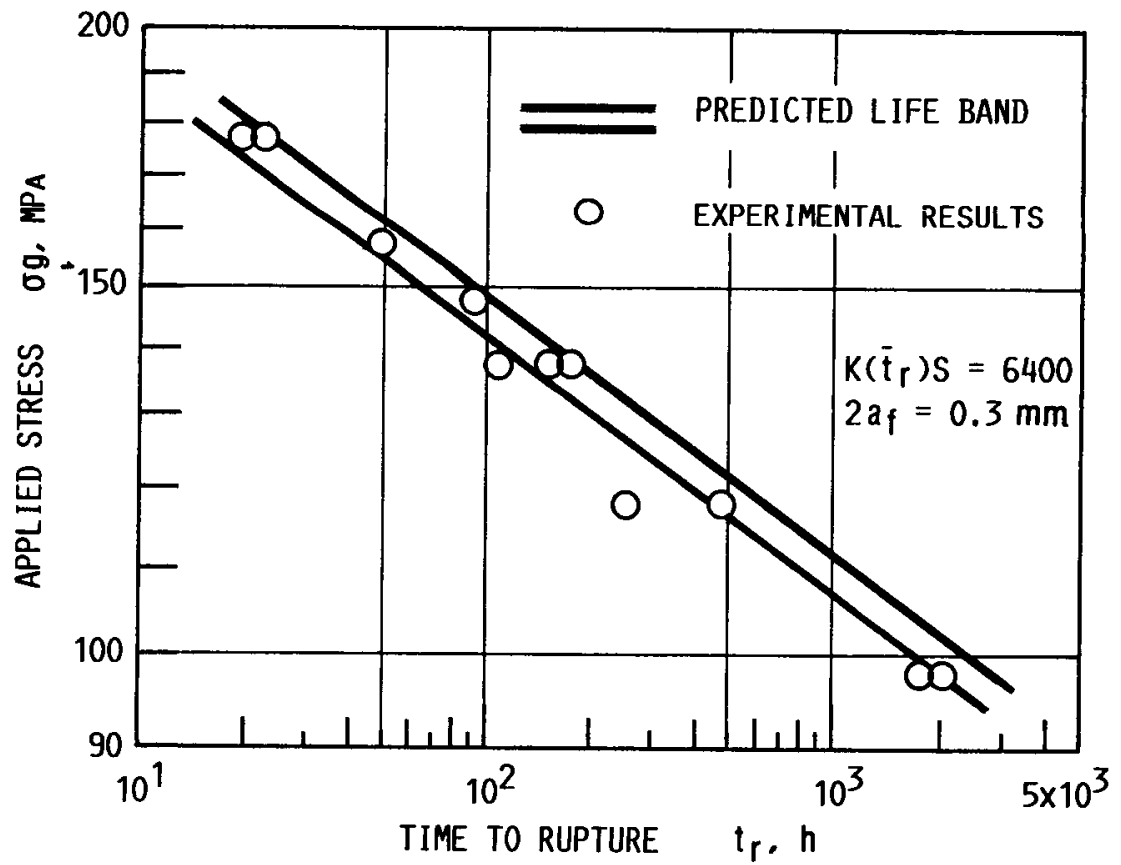

FIGURE 11. - COMPARISON OF CREEP LIFE BETWEEN PREDICTION AND EXPERIMENT. 


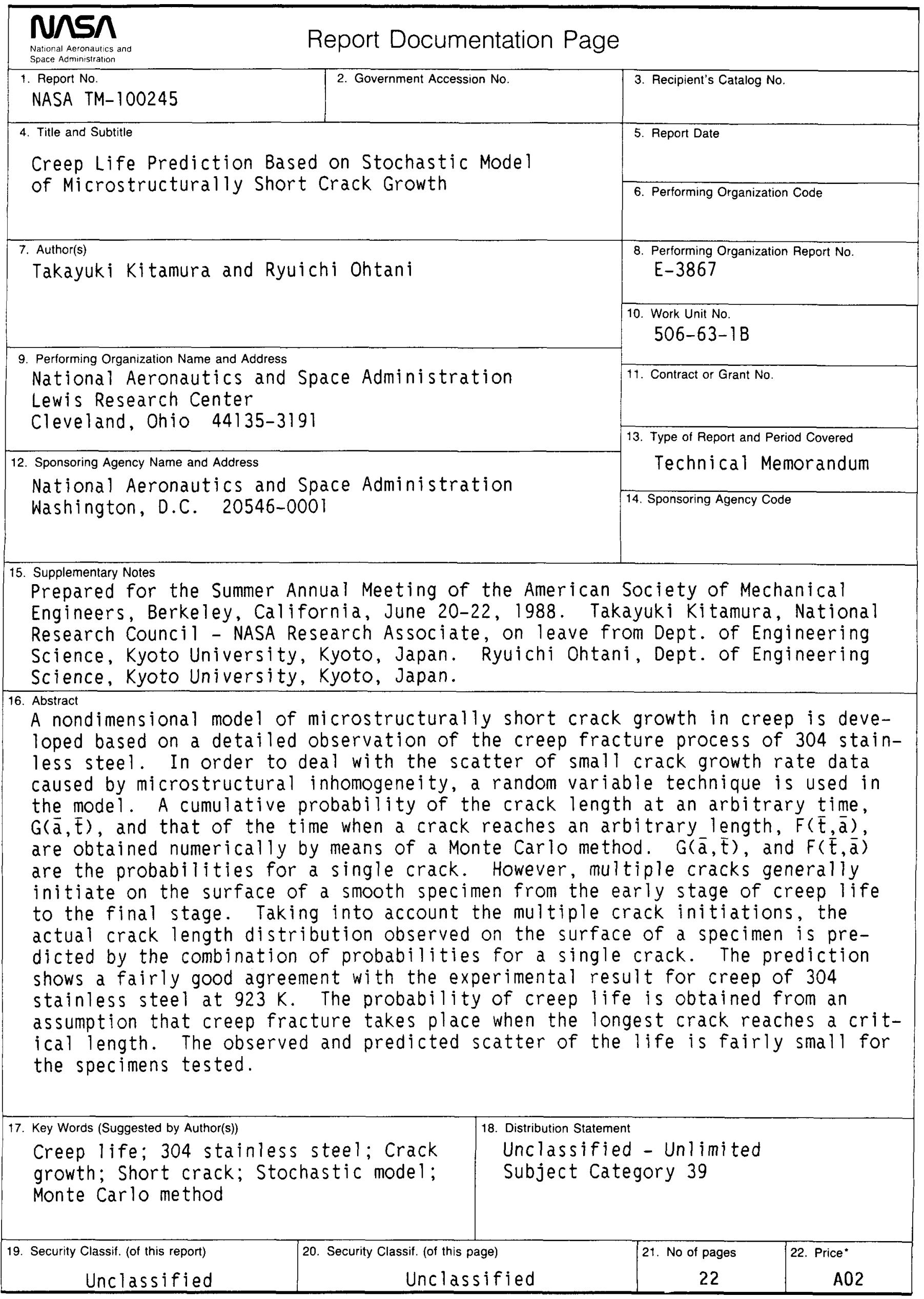

